\title{
PENYELESAIAN MASALAH KONTROL OPTIMAL KONTINU YANG MEMUAT FAKTOR DISKON
}

\author{
DALIANI \\ Program Studi Matematika, \\ Fakultas Matematika dan Ilmu Pengetahuan Alam, Universitas Andalas, \\ Kampus UNAND Limau Manis Padang, Indonesia, \\ daliani.lia99@gmail.com
}

\begin{abstract}
Abstrak. Masalah kontrol optimal kontinu merupakan masalah kotrol optimal yang saat ini telah digunakan dalam berbagai bidang. Tujuan masalah kontrol optimal kontinu ini adalah memaksimumkan fungsi tujuan $J(u)$ yang memuat faktor diskon $e^{-\alpha t}$. Eksistensi dari pengontrol $u(t)$ sangat bergantung pada konstrain yang diberikan. Oleh karena itu, akan dikaji syarat cukup yang menjamin eksistensi kontrol optimal $u^{*}(t)$ yang memenuhi konstrain yang berupa persamaan diferensial $\dot{x}(t)=g(t, x(t), u(t))$. Selain itu diberikan beberapa contoh sebagai ilustrasi untuk memperkuat keberlakuan syarat cukup tersebut.
\end{abstract}

Kata Kunci: Kontrol optimal, persamaan Lagrange, Current Value Hamiltonian

\section{Pendahuluan}

Masalah kontrol otimal kontinu merupakan masalah penentuan suatu pengontrol $u(t), t \in \mathbb{R}$ yang memaksimumkan fungsi tujuan

$$
\begin{aligned}
\max _{u} J(u) & =S(x(T), T)+\int_{0}^{T} f(t, x(t), u(t)) d t \\
\text { s.t } \dot{x}(t) & =g(t, x(t), u(t)), t \in[0, T] \\
x(0) & =x_{0}, \quad x(T) \text { diberikan atau bebas, }
\end{aligned}
$$

di mana $x$ adalah variabel keadaan dan $u$ adalah variabel kontrol, dengan $x, u \in$ $C^{2}([0, T])=\{y(t) \mid \ddot{y}$ ada dan kontinu pada $[0, T]\}$.

Model optimisasi (1.1) sering muncul dalam aplikasi, terutama dalam biologi [6], kesehatan [2], ekonomi [3]. Khusus dalam bidang ekonomi, fungsi tujuan yang digunakan sering memuat suatu faktor diskon $e^{-\alpha t}$, di mana $0<\alpha<1$, sehingga fungsi tujuan berbentuk

$$
J(u)=S(x(T), T)+\int_{0}^{T} e^{-\alpha t} f(t, x(t), u(t)) d t
$$

Dalam paper ini, akan dikaji syarat cukup yang menjamin eksistensi pengontrol $u(t)$ yang memenuhi persamaan diferensial $\dot{x}(t)=g(t, x(t), u(t))$ dan memaksimumkan fungsi objektif (1.2). 


\section{Penyelesaian Masalah Kontrol Optimal yang Memuat Faktor Diskon}

Perhatikan masalah kontrol optimal berikut.

$$
\begin{aligned}
\max _{u} J(u) & =S(x(T), T)+\int_{0}^{T} e^{-\alpha t} f(t, x(t), u(t)) d t, \\
\text { s.t. } \quad \dot{x}(t) & =g(t, x(t), u(t)), \\
x(0) & =x_{0}, \quad x(T) \quad \text { bebas atau diberikan, }
\end{aligned}
$$

di mana $x \in C^{2}([0, T])$ adalah variabel keadaan dan $u \in C^{2}([0, T])$ adalah variabel kontrol. Selanjutnya, akan ditentukan pengontrol $u$ yang memenuhi konstrain (2.1) sekaligus memaksimumkan fungsi tujuan (2.1).

Definisikan Lagrangian sebagai berikut.

$$
\begin{aligned}
L(x, u, \lambda)= & S(x(T), T)+\int_{0}^{T} e^{-\alpha t}(f(t, x(t), u(t)) \\
& +\lambda(t)(g(t, x(t), u(t))-\dot{x}(t))) d t,
\end{aligned}
$$

di mana $\lambda(t)$ adalah pengali Lagrange. Asumsikan $\alpha=0$, maka persamaan (2.2) menjadi

$$
\begin{aligned}
L(x, u, \lambda)= & S(x(T), T)+\int_{0}^{T}[f(t, x(t), u(t))+\lambda(t) g(t, x(t), u(t))-\lambda(t) \dot{x}(t)] d t \\
= & S(x(T), T)+\int_{0}^{T}[f(t, x(t), u(t))+\lambda(t)(g(t, x(t), u(t)) \\
& +x(t) \dot{\lambda}(t)] d t+\lambda(0) x(0)-\lambda(T) x(T) .
\end{aligned}
$$

Definisikan fungsi $H$ sebagai berikut.

$$
H=f(t, x(t), u(t))+\lambda g(t, x(t), u(t)) .
$$

Maka (2.3) dapat ditulis menjadi

$$
\begin{aligned}
L= & S(x(T), T)+\int_{0}^{T}[H(t, x(t), u(t), \lambda(t))+x(t) \dot{\lambda}(t)] d t \\
& +\lambda(0) x(0)-\lambda(T) x(T) .
\end{aligned}
$$

Fungsi $H$ ini disebut sebagai fungsi Hamiltonian [5].

Misalkan $u^{*}(t)$ adalah kontrol optimal dan $x^{*}(t)$ adalah keadaan optimal yang diinginkan, maka

$$
\begin{aligned}
u(t) & =u^{*}(t)+\varepsilon p(t), \\
x(t) & =x^{*}(t)+\varepsilon q(t), \\
x(T) & =x^{*}(T)+\varepsilon d x(T),
\end{aligned}
$$

di mana $p(t), q(t) \in C^{2}([0, T])$ dan $\varepsilon>0$.

Dengan menggunakan syarat ekstrim $\frac{\partial L}{\partial \varepsilon}=0$, diperoleh

$$
\frac{\partial L}{\partial \varepsilon}=\frac{\partial S(x(T, \varepsilon), T)}{\partial \varepsilon}+\int_{0}^{T}\left(\frac{\partial H}{\partial \varepsilon}+\dot{\lambda} \frac{\partial x}{\partial \varepsilon}\right) d t-\lambda(T) \frac{\partial x(T, \varepsilon)}{\partial \varepsilon}=0 .
$$


Dengan menggunakan aturan rantai, maka (2.6) menjadi

$$
\frac{\partial L}{\partial \varepsilon}=\left(\frac{\partial S}{\partial x}-\lambda(T)\right) d x(T)+\int_{0}^{T}\left[\left(\frac{\partial H}{\partial x}+\dot{\lambda}\right) q(t)+\frac{\partial H}{\partial u} p(t)\right] d t
$$

Dari (2.7) dan konstrain pada (2.1) diperoleh bahwa syarat perlu agar $u^{*}$ merupakan kontrol optimal adalah

$$
\begin{aligned}
\dot{x} & =\frac{\partial H}{\partial \lambda}=g(t, x(t), u(t)), \\
\dot{\lambda} & =-\frac{\partial H}{\partial x} \\
\frac{\partial H}{\partial u} & =0 \\
\lambda(T) & =\frac{\partial S}{\partial x} .
\end{aligned}
$$

Teorema 2.1. [4] Untuk masalah kontrol optimal (2.1), misalkan fungsi $f$ dan $g$ memenuhi syarat berikut,

(1) fungsi yang kontinu dalam $(x, u, t)$,

(2) memiliki turunan parsial pertama terhadap $x$ dan $u$,

(3) concave dalam $(x, u)$ untuk setiap $(x, u) \in C^{2}([0, T])$.

Jika $\left(t, x^{*}, u^{*}\right)$ memenuhi (2.8) maka $u^{*}$ memaksimumkan fungsi tujuan (2.1) dengan $\alpha=0$.

Bukti. Karena $f$ concave dalam $(x, u)$, maka berlaku

$$
\begin{aligned}
J(u)-J\left(u^{*}\right)= & S(x(T), T)-S\left(x^{*}(T), T\right)+\int_{0}^{T} f(t, x, u)-f\left(t, x^{*}, u^{*}\right) d t, \\
\leq & S_{x}\left(x^{*}(T), T\right)\left(x(T)-x^{*}(T)\right), \\
& \quad+\int_{0}^{T}\left[f_{x}\left(t, x^{*}, u^{*}\right)\left(x-x^{*}\right)-f_{u}\left(t, x^{*}, u^{*}\right)\left(u-u^{*}\right)\right] d t, \\
\leq & S_{x}\left(x^{*}(T), T\right)\left(x(T)-x^{*}(T)\right) \\
& \quad+\int_{0}^{T}\left[-\left(\dot{\lambda}+\lambda g_{x}\right)\left(x-x^{*}\right)-\lambda g_{u}\left(u-u^{*}\right)\right] d t, \\
= & S_{x}\left(x^{*}(T), T\right)\left(x(T)-x^{*}(T)\right)-\lambda(T)\left(x(T)-x^{*}(t)\right)+\lambda(0)\left(x(0)-x^{*}(0)\right) \\
& \quad+\int_{0}^{T}\left[\lambda\left(\dot{x}-\dot{x}^{*}\right) d t-\lambda g_{x}\left(x-x^{*}\right)-\lambda g_{u}\left(u-u^{*}\right)\right] d t, \\
= & \lambda(0)\left(x(0)-x^{*}(0)\right)+\int_{0}^{T} \lambda\left[g(t, x, u)-g\left(t, x^{*}, u^{*}\right)\right. \\
& \left.\quad-g_{x}\left(x-x^{*}\right)-g_{u}\left(u-u^{*}\right)\right] d t .
\end{aligned}
$$

Karena $f$ concave dalam $(x, u)$, maka komponen dalam integral adalah non positif. Selanjutnya, karena $x(0)$ tetap, maka $x(0)=x_{0}=x^{*}(0)$. Sehingga $J(u)-J\left(u^{*}\right) \leq 0$, atau $J(u) \leq J\left(u^{*}\right)$, yang memperlihatkan bahwa $u^{*}$ merupakan pemaksimum dari masalah (2.1). 
Selanjutnya, jika $0<\alpha<1$ maka Hamiltonian dapat ditulis sebagai

$$
H=e^{-\alpha t} f(t, x(t), u(t))+\lambda g(t, x(t), u(t)) .
$$

Dengan menggunakan Current Value Hamiltonian, maka syarat perlu (2.8) menjadi

$$
\begin{aligned}
\dot{x} & =\frac{\partial H}{\partial \lambda}=\frac{\partial \mathcal{H}}{\partial \lambda} e^{-\alpha t}=\frac{\partial \mathcal{H}}{\partial m}, \\
\dot{\lambda} & =-\mathcal{H}_{x}+\alpha m(t), \\
\frac{\partial \mathcal{H}}{\partial u} & =\mathcal{H}_{u}=0, \\
m(T) & =\frac{\partial S}{\partial x} e^{\alpha t} .
\end{aligned}
$$

Proses di atas telah membuktikan teorema berikut untuk menentukan solusi optimal masalah kontrol optimal (2.1).

Teorema 2.2. [5] Jika $\left(x^{*}(t), u^{*}(t)\right)$ yang memenuhi kondisi pada (2.11) dan $H$ adalah concave dalam $(x, u)$ maka $u^{*}(t)$ adalah optimal untuk masalah kontrol optimal (2.1).

\section{Contoh}

Perhatikan masalah kontrol optimal berikut.

$$
\begin{aligned}
\max _{u} J(u) & =\int_{0}^{1} \frac{1}{2} u^{2} e^{-0.5 t} d t \\
\text { s.t. } \dot{x} & =-x+u, \\
x(0) & =2, x(1) \text { bebas. }
\end{aligned}
$$

Akan ditentukan kontrol optimal dari masalah di atas.

$$
\mathcal{H}(x, u, t)=\frac{1}{2} u^{2}+m(-x+u)
$$

Berdasarkan (2.11) diperoleh syarat ekstrim sebagai berikut.

(1) $\frac{\partial \mathcal{H}}{\partial u}=u+m=0 \Rightarrow u=-m$,

(2) $\dot{m}=-\frac{\partial \mathcal{H}}{\partial x}+\alpha m$,

$$
\dot{m}-1.5 m=0,
$$

(3) $\dot{x}=-x+u$

$$
\dot{x}+x=u \text {. }
$$

Karena $x(1)$ bebas maka $\lambda(1)=0$. Misalkan $D=\frac{d}{d t}$, maka syarat ekstrim (2) dan (3) dapat disubtitusikan sebagai berikut.

$$
\begin{aligned}
(D-1.5)(\dot{x}+x) & =(D-1.5)(-m), \\
D(\dot{x}+x)-1.5(\dot{x}+x) & =D(-m)-(1.5)(-m), \\
\ddot{x}+\dot{x}-1.5 \dot{x}-1.5 x & =-(\dot{m}-1.5 m), \\
\ddot{x}-0.5 \dot{x}-1.5 x & =0 .
\end{aligned}
$$

Persamaan karakteristik dari persamaan (3.1) adalah

$$
r^{2}-0.5 r-1.5=0,
$$


sehingga diperoleh solusi

$$
x(t)=A e^{1.5 t}+B e^{-t},
$$

akibatnya

$$
\begin{aligned}
u & =(D+1) x=(D+1)\left(A e^{1.5 t}+B e^{-t}\right)=2.5 A e^{1.5 t} \\
m & =-u=-\left(2.5 A e^{1.5 t}\right) .
\end{aligned}
$$

Selanjutnya diperoleh syarat awal sebagai berikut.

$$
\begin{gathered}
x(0)=A+B=2 . \\
m(1)=-2.5 A e^{1.5} .
\end{gathered}
$$

Dari (3.3) dan (3.4) diperoleh

$$
\begin{aligned}
& A=2-\frac{2}{e^{1.5}}=\frac{2\left(e^{1.5}-1\right)}{e^{1.5}}, \\
& B=\frac{2}{e^{1.5}} .
\end{aligned}
$$

Jadi, kontrol optimalnya adalah sebagai berikut.

$$
u^{*}(t)=2.5 A e^{1.5 t}=2.5\left(\frac{2\left(e^{1.5}-1\right)}{e^{1.5}}\right) e^{1.5 t},
$$

dan keadaan optimal adalah :

$$
x^{*}(t)=\left(\frac{2\left(e^{1.5}-1\right)}{e^{1.5}}\right) e^{1.5 t}+\frac{2}{e^{1.5}} e^{-t} .
$$

\section{Ucapan Terima kasih}

Penulis mengucapkan terima kasih kepada Bapak Dr. Muhafzan, Ibu Dr. Lyra Yulianti, Bapak Dr. Admi Nazra dan Bapak Zulakmal, M.Si yang telah memberikan masukan dan saran sehingga paper ini dapat diselesaikan dengan baik.

\section{Daftar Pustaka}

[1] Chiang, A. C. 1992. Element of Dynamic Optimization. Science Typographers Inc, Singapore.

[2] Fadila, Ana. 2012. Kontrol Optimal pada Model Epidemik Sir. Jurnal-S1 Jurusan Matematika Universitas Brawijaya, Malang.

[3] Furqon, Ahmad. 2006. Model Respon Penjualan Saham Terhadap Iklan. SkripsiS1 Jurusan Matematika UI, Jakarta.

[4] Grass, Dieter, dkk. 2008. Optimal Control of Nonlinear Processes. Springer, Berlin.

[5] Kamien, M.I. dan N.L. Schwartz. 1991. Dynamic Optimization: The Calculus of Variations and Optimal Control in Economics and Management. North Holland, Amsterdam.

[6] Lesnussa, Y. A. 2010. Aplikasi Kendali Optimum dalam Penentuan Interval Waktu dan Dosis Optimal pada Kemoterapi Kanker. Jurnal-S1. ITS, Surabaya 